Bull. Mater. Sci., Vol. 17, No. 6, November 1994, pp. 1049-1055. (C) Printed in India.

\title{
Successively pulse plated cadmium selenide films and their photoelectrochemical behaviour
}

\author{
V SUBRAMANIAN, K R MURALI, N RANGARAJAN and \\ A S LAKSHMANAN \\ Central Electrochemical Research Institute, Karaikudi 623 006, India
}

\begin{abstract}
In successive pulse plating, the pulse deposition is repeated after a definite duration of plating preceded by a mild cleaning of the electrode and with a fresh deposition bath for the same duration. In this study, CdSe films were deposited on Ti substrates by successive pulse plating from a bath containing $\mathrm{CdSO}_{4}$ and $\mathrm{SeO}_{2}$ at a current density of $80 \mathrm{~mA} \mathrm{~cm}$ and a duty cycle of $3.3 \%$ for a duration of $30 \mathrm{~min}$. The films heat-treated to $550^{\circ} \mathrm{C}$ for $20 \mathrm{~min}$ in argon atmosphere, were polycrystalline with a hexagonal structure. At an illumination of $60 \mathrm{~mW} \mathrm{~cm}$, a conversion efficiency of $4.5 \%$ for the photoetched film and $1.7 \%$ for the chemically etched one were determined.
\end{abstract}

Keywords. Cadmium selenide; pulse plating.

\section{Introduction}

$n$-CdSe has been used as a photoanode in photoelectrochemical (PEC) cells to give a high power conversion efficiency, both in single crystal and polycrystalline forms. In recent years, there has been considerable work in the study of polycrystalline electrodes for PEC cells, since $70 \%$ of the single crystal efficiency can be obtained with low cost polycrystalline films. Vacuum evaporation, spray pyrolysis, chemical bath deposition, slurry coating, electrodeposition etc have been employed earlier for the preparation of these films. We report here the results on successively pulse plated CdSe films.

Metal deposits obtained by pulse plating show distinct advantages like improved deposit distribution, adhesion and lower impurity content compared to conventional dc electrodeposition. The properties of the deposit can be varied by varying the current density and duty cycle. Higher nucleation rates are possible with pulse plating (Rehrig et al 1977; Popov et al 1980; Lam et al 1983). Crack-free hard deposits with low porosity and low internal stress are obtainable with pulsing (Devaraj et al 1989a, b). An increased average grain size and uniform grain distribution (compared to conventional electrodeposition) are noticed in pulse plated films.

The main purpose of carrying out successive pulse plating (pulse deposition repeated after a definite duration of plating preceded by a mild cleaning of the electrode and with a fresh deposition bath for the same duration) is to obtain higher film thicknesses which, in turn will yield higher grain size (Saitoh et al 1976) due to better nucleation sites, yielding higher conversion efficiencies (Lanza and Hovel 1980; Pandey et al 1991) for photoelectrochemical cells.

This paper reports the comparative PEC results obtained with successively pulse plated CdSe films with those obtained by conventional pulse plating. The improvements in the output parameters have justified the expectations. 


\section{Experimental}

CdSe films ( $3 \mu \mathrm{m}$ thick) were pulse plated cathodically at room temperature on $\mathrm{Ti}$ substrates employing a bath of $0.5 \mathrm{M} \mathrm{CdSO}_{4}$ and $0.005 \mathrm{M} \mathrm{SeO}_{2}$ which was kept stirred. Graphite was used as the other electrode with an inter-electrode distance of $2 \mathrm{~cm}$. A current density of $80 \mathrm{~mA} \mathrm{~cm}$ was employed with an on-time of $1 \mathrm{sec}$ and off-time of $29 \mathrm{sec}$ making the duty cycle $3.3 \%$. Then, the substrates along with the deposited films were taken out, washed well with triple distilled water and introduced in a fresh bath solution of the same composition for a second pulse deposition (which we call successive pulse plating). The other parameters such as current density, duty cycle etc were kept constant for the successive pulse deposition and repeated for the same duration of $30 \mathrm{~min}$. The thickness of the films were found to be $5 \mu \mathrm{m}$.

The films were heat treated at $550^{\circ} \mathrm{C}$ for a duration of $20 \mathrm{~min}$ in argon atmosphere, and characterized by $\mathrm{X}$-ray diffraction using $\mathrm{CuK}_{\alpha}$ radiation. Optical absorption studies were carried out employing a Hitachi U 3400 UV-VIS-NIR spectrophotometer. Surface morphology was examined by $35 \mathrm{CF}$ JEOL scanning electron microscope.

The PEC cell consisted of the photoelectrode and a graphite counter electrode with $1 \mathrm{M}$ alkaline polysulphide as the electrolyte. The light source was an Oriel $250 \mathrm{~W}$ tungsten halogen lamp. The photon flux reaching the electrode surface was measured by a CEL Suryamapi. After heat treatment, the electrodes were etched chemically in $1: 3 \mathrm{HCl}$ for $5 \mathrm{sec}$ and rinsed in triple distilled water. Photoetching was performed by shorting the photoelectrode and the counter electrode in $1: 3$ $\mathrm{HCl}$ for different durations in the range of 5 to $60 \mathrm{sec}$ under an illumination of $60 \mathrm{~mW} \mathrm{~cm}{ }^{-2}$. $C-V$ measurements were carried out in polysulphide electrolyte using an EG and G PARC impedance system at different frequencies. Quantum efficiencies at different wavelengths in the range $550-820 \mathrm{~nm}$ were measured employing an Applied Photophysics $\mathrm{f} / 3.4$ monochromator with a resolution of $0.2 \mathrm{~nm}$.

\section{Results and discussion}

The X-ray diffraction pattern of a successively pulse plated film is shown in figure 1. The diffractograms indicate the polycrystalline nature of the film with all the major peaks corresponding to hexagonal CdSe. Peaks corresponding to elemental $\mathrm{Se}$ or $\mathrm{Cd}$ are not present. Surface morphology of the films indicate an average grain size of $3 \mu \mathrm{m}$. The grain size is found to increase from 1 to $3 \mu \mathrm{m}$ after successive pulse deposition.

The power output characteristics of the PEC cells employing the regular pulse deposited and successively deposited films are shown in figure 2 . While for the regular pulse deposited films, a $V_{\mathrm{oc}}$ of $435 \mathrm{mV}, J_{\mathrm{sc}}$ of $3.2 \mathrm{~mA} \mathrm{~cm}$, fill factor (FF) of 0.43 and efficiency $(\eta)$ of $1 \%$ are obtained, for the successively pulse plated films a $V_{\mathrm{oc}}$ of $450 \mathrm{mV}, J_{\mathrm{sc}}$ of $5 \mathrm{~mA} \mathrm{~cm}$, FF of 0.46 and $\eta$ of $1.7 \%$ are obtained. From the $I-V$ curves, series resistance $\left(R_{\mathrm{s}}\right)$ values of $58 \mathrm{ohms}$ and $40 \mathrm{ohms}$ and shunt resistance $\left(R_{\mathrm{sh}}\right)$ values of $1.66 \mathrm{kohms}$ and $3 \mathrm{kohms}$ have been obtained for the two cases respectively. The enhanced output for the successively pulse plated films is due to their increased grain size. After a $60 \mathrm{sec}$ photoetch of the successively pulse plated films, the output parameters are: $V_{\mathrm{oc}}=475 \mathrm{mV}, J_{\mathrm{sc}}=11.7 \mathrm{~mA} \mathrm{~cm}$, FF 
$=0.48$ and $\eta=4.8 \%$. The cell shows an $R_{\mathrm{s}}$ of $18 \mathrm{ohms}$ and high $R_{\mathrm{sh}}$ of $3.5 \mathrm{kohms}$. For the present study, a large number of films [50] had been prepared. The variation in efficiency among the cells was from $4.5 \%$ to $4.8 \%$. Other measurements carried out on the successively pulse plated films are $V_{\mathrm{fb}}$, quantum efficiency, minority carrier diffusion length, diffusion layer width and the conductivity.

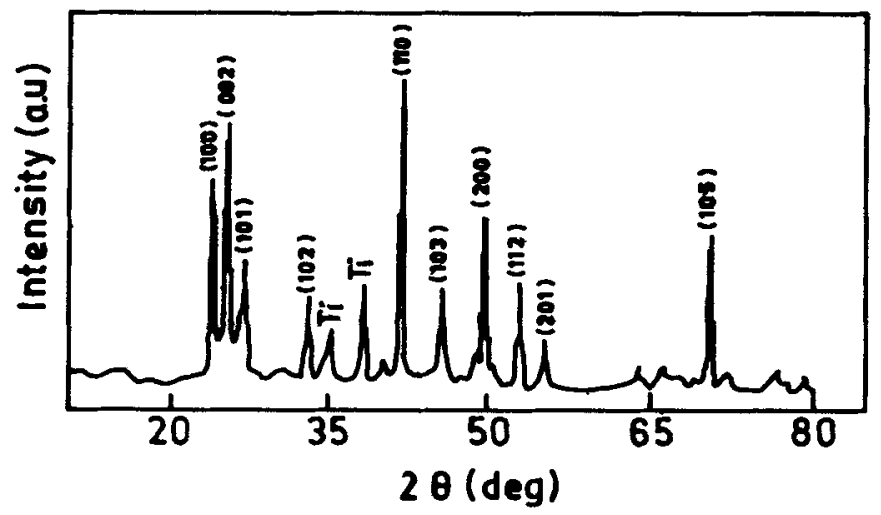

Figure 1. X-ray diffraction pattern of the CdSe film.

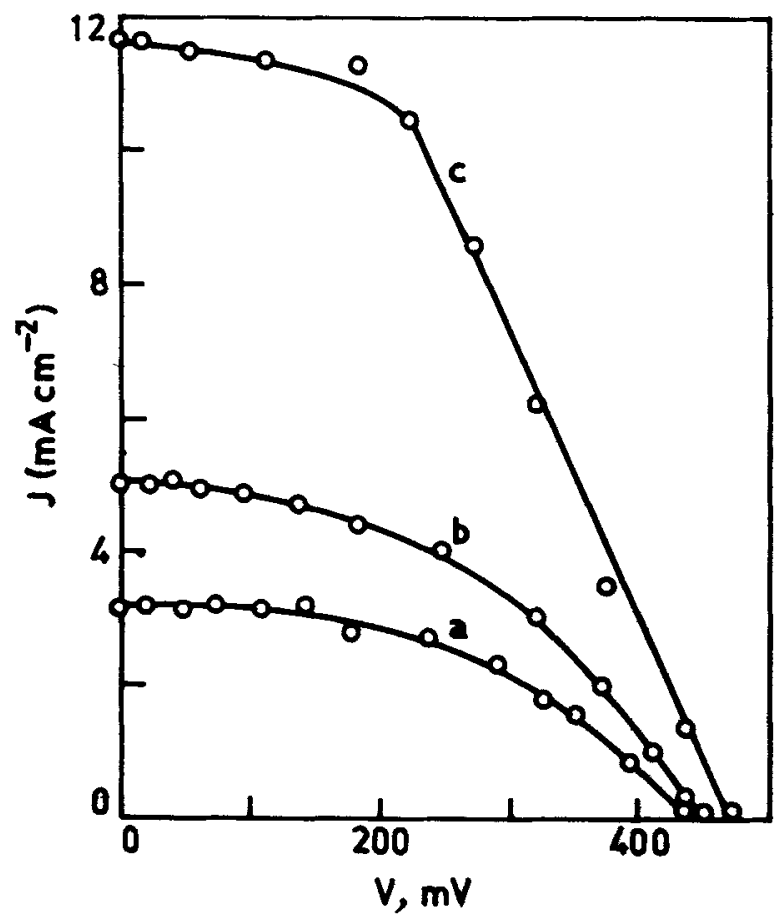

Figure 2. Power output characteristics of the CdSe film. a. single pulse deposited, b. successive pulse deposited and c. after photoetching. 
Mott-Schottky plot for a frequency of $10 \mathrm{kHz}$ in $1 \mathrm{M}$ polysulphide electrolyte is shown in figure 3 . The linearity of the plot suggests that the impurities are uniformly ionized (Ramprakash et al 1988). From the extrapolated intercept on $Y$-axis, a flat band potential $\left(V_{\mathrm{fb}}\right)$ of $+1.19 \mathrm{~V}$ vs SCE was obtained. The plot indicates $p$-type behaviour for the films. $p$-type behaviour has also been reported by Hodes et al (1992) for the quantum box CdSe semiconducting films and the reason for the $p$-type behaviour has not been well understood. From the slope of the plot, a value of $5.65 \times 10^{16} \mathrm{~cm}^{-3}$ has been deduced for the carrier density.

Quantum efficiency $(\phi)$ was evaluated from the spectral response measurements by employing the following expression (Segui et al 1991)

$$
\phi=\frac{1240 J_{s c}}{\lambda P},
$$

where $J_{\mathrm{sc}}$ is current density expressed in $\mathrm{A} \mathrm{cm} \mathrm{cm}^{-2} ; \lambda$ the wavelength expressed in $\mathrm{nm}$ and $P$ the radiant power absorbed in the photoactive region, expressed in $\mathrm{W} \mathrm{cm} \mathrm{cm}^{-2}$. Figure 4 shows the variation of quantum efficiency in the wavelength range $550-820 \mathrm{~nm}$.

A peak quantum efficiency of 0.61 is observed in the region $650-700 \mathrm{~nm}$, agreeing with the band gap of the material.

From Gartner's photocurrent equation for a metal-semiconductor junction, quantum efficiency, $\phi$, (Russak et al 1980) follows the relation

$$
\phi=1-\left(e^{-\alpha w} / 1+\alpha L_{p}\right) \text {, }
$$

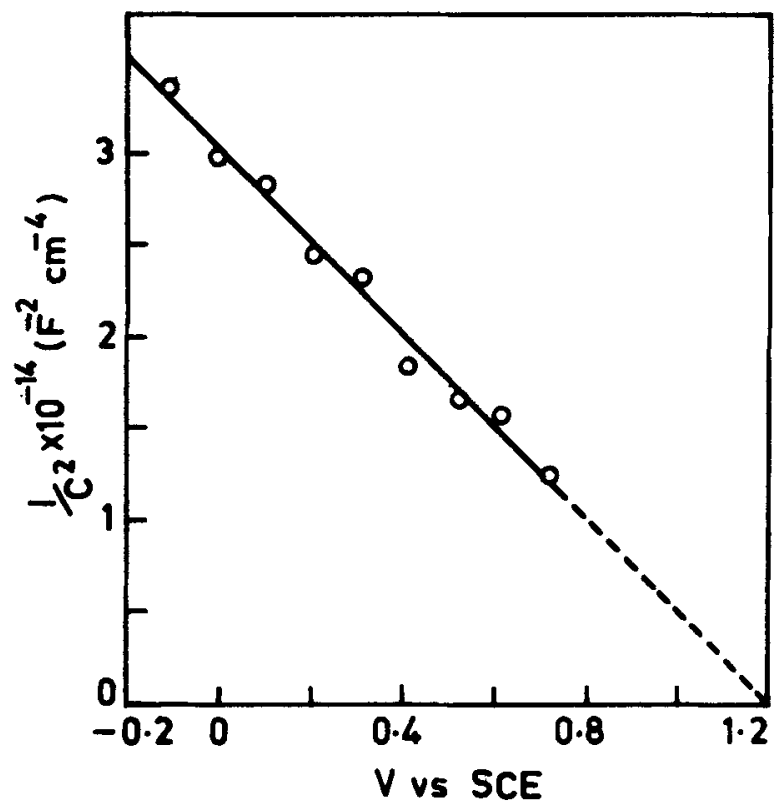

Figure 3. Mott-Schottky plot of successively pulse plated CdSe film in $1 \mathrm{M}$ polysulphide «. $10 \mathrm{kHz}$. 
where $W$ is the depletion layer width given by

$$
W=\left[\left(2 \varepsilon \varepsilon_{\mathrm{o}} / q N_{\mathrm{D}}\right)\left(V-V_{\mathrm{fb}}\right)\right]^{1 / 2},
$$

$q$ is the electron charge, $\alpha$ the absorption coefficient, $L_{p}$ the diffusion length of the minority carriers, $\varepsilon$ the dielectric constant of the semiconductor, $\varepsilon_{0}$ the permittivity of free space, $V$ the electrode potential, $V_{\mathrm{fb}}$ the flat band potential and $N_{\mathrm{D}}$ the doping density. By choosing a wavelength of relatively weak absorption so that $L_{\mathrm{p}} \ll 1$ and $W \ll 1$ (Pandey et al 1991), the following relationship is obtained

$$
\phi=L_{p} \text {. }
$$

Hence

$$
\phi^{-1}=\left(L_{p}\right)^{-1} .
$$

A plot of $\phi^{-1}$ vs $\alpha^{-1}$ is shown in figure 5. $L_{p}$ is obtained from the inverse of the slope and is found to be $0.98 \mu \mathrm{m}$. This value of $L_{p}$ is in close agreement with the value of $0.8 \mu \mathrm{m}$ reported (Russak et al 1980) for a CdSe film obtained by the dc electrodeposition technique.

In order to obtain $W,(2)$ can be rearranged as

$$
W=-\ln \left[(1-\phi)\left(1+\alpha L_{\mathrm{p}}\right)\right] / \alpha
$$

Substituting the corresponding values of $\alpha$ and $\phi$ when $W \ll 1$, we obtain $W=$ $0.3 \mu \mathrm{m}$. The maximum reported value (Gutierrez and Salvador 1987) of $W$ for CdSe films is $0.7 \mu \mathrm{m}$. The reported conversion efficiencies are $11.7 \%$ for a PEC cell

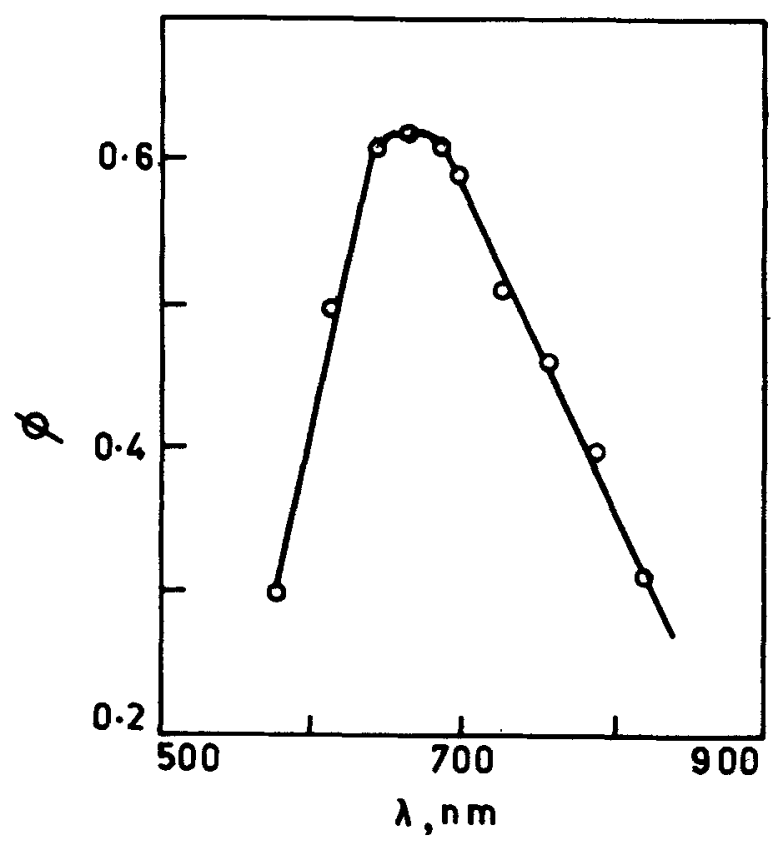

Figure 4. Variation of quantum efficiency $(\phi)$ with wavelength $(\lambda)$ for the PEC cell employing successively pulse plated CdSe films. 


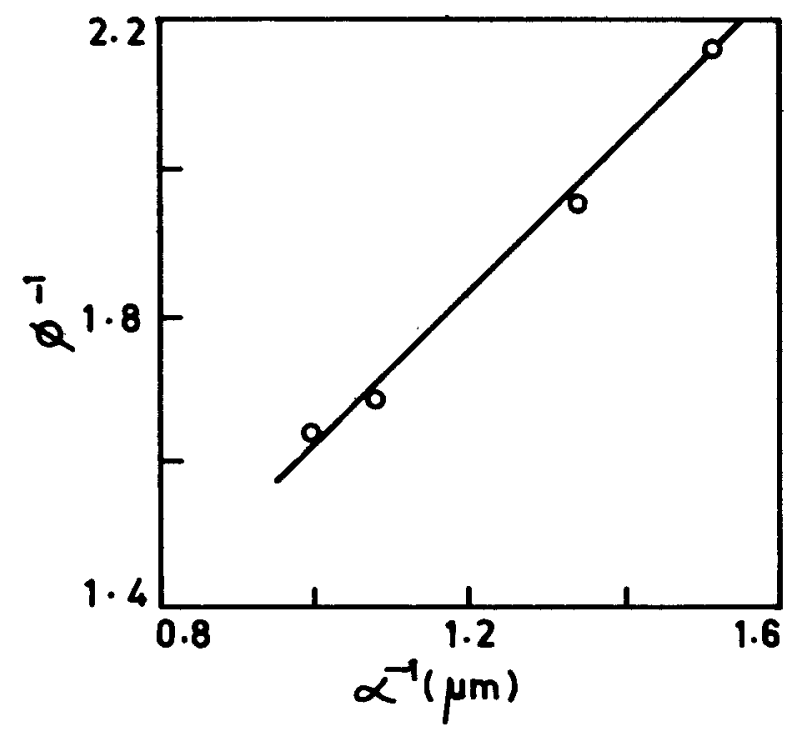

Figure 5. Variation of inverse quantum efficiency $\left(\phi^{-1}\right)$ with reciprocal of absorption coefficient $\left(\alpha^{-1}\right)$ for the PEC cell.

with a chemically deposited polycrystalline CdSe film (Savadogo and Mandal 1992) with surface modification and $7.3 \%$ with the film obtained by the dc electrodeposition technique (Szabo and Cocivera 1986) and $7.4 \%$ with the films obtained by brush plating technique (Murali et al 1994).

From the measurement of cross-plane resistance of the CdSe film, the conductivity has been found to be $0.02 \mathrm{ohm}^{-1} \mathrm{~cm}^{-1}$. Employing the values of $N_{\mathrm{D}}$, the mobility of the electrons is found to be $2.4 \mathrm{~cm}^{2} \mathrm{~V}^{-1} \mathrm{sec}^{-1}$. This value is in agreement within the range of values reported (Wynands and Cocivera 1992) for the electrodeposited CdSe films.

\section{Conclusion}

The results of the present study indicate that successive pulse plating improves PEC characteristics. There is reason to expect that quantum efficiency and power conversion efficiency can be enhanced further by optimizing the heat treatment and etching steps and also pulse parameters.

\section{Acknowledgement}

The authors are grateful to the Ministry of Non-Conventional Energy Sources, Government of India, for financial support.

\section{References}

Devaraj G, Vasu K I and Seshadri N 1989a Bull. Electrochem. 5333

Devaraj G, Ramesh Bapu G N K, Ayyapparaju J and Guruviah S 1989b Bull. Electrochem. 5448 
Gutierrez M T and Salvador P 1987 Sol. Energy Mater. 1599

Hodes G, Howell I D J and Peter L M 1992 J. Electrochem. Soc. 1393136

Lam J L, Kaike A, Ohno I and Naruyama S 1983 Kinzoku Hyomen Gijutsu 34428

Lanza C and Hovel H 1980 IEEE Trans. Electron. Dev. ED 272085

Murali K R, Subramanian V, Rangarajan N, Lakshmanan A S and Rangarajan S K 1994 J. Electroanal. Chem. 36895

Pandey R K, Kumar S R, Rooz A J N and Chandra S 1991 Thin Solid Films 2001

Popov K I, Maksimoric M D, Ocokoljic B M and Lazarevic B J 1980 Surf. Technol. 1199

Ramprakash Y, Subramanian V, Krishnakumar R, Lakshmanan A S and Venkatesan V K 1988 J. Power Sources 3441

Rehrig D L, Leidheiser H and Notis M R 1977 Plat. Surf. Finish 6440

Russak M, Reichman H, Witzke H, Deb S K and Chan S N 1980.J. Electrochem. Soc. 127725

Saitoh T, Matsubara S and Minagawa S 1976 J. Electrochem. Soc. 123403

Savadogo O and Mandal K C 1992 Mater. Chem. Phys. 31301

Segui J, Hotchandani S, Baddau D and Leblanc R M 1991 J. Phys. Chem. 958807

Szabo J P and Cocivera M $1986 J$. Electrochem. Soc. 1331247

Wynands $H$ and Cocivera M 1992 J. Electrochem. Soc. 36895 